\title{
Article \\ Self-Acting Formation of an ANFO Similar Type of Explosive under Fire Conditions: A Case Study
}

\author{
Paweł Wolny ${ }^{1, *}$, Norbert Tuśnio ${ }^{2}$, Artur Lewandowski ${ }^{1}$, Filip Mikołajczyk ${ }^{1}$ and Sławomir Kuberski ${ }^{1}$ \\ 1 Faculty of Process and Environmental Engineering, Łódź University of Technology, 90-924 Łódź, Poland; \\ artur.lewandowski@p.lodz.pl (A.L.); filip.mikolajczyk@p.lodz.pl (F.M.); slawomir.kuberski@p.lodz.pl (S.K.) \\ 2 Faculty of Safety Engineering and Civil Protection, The Main School of Fire Service, 01-629 Warsaw, Poland; \\ ntusnio@sgsp.edu.pl \\ * Correspondence: pawel.wolny@p.lodz.pl; Tel.: +48-501-223-717
}

check for updates

Citation: Wolny, P.; Tuśnio, N.;

Lewandowski, A.; Mikołajczyk, F.; Kuberski, S. Self-Acting Formation of an ANFO Similar Type of Explosive under Fire Conditions: A Case Study. Energies 2021, 14, 6980.

https://doi.org/10.3390/en14216980

Academic Editor: Ernesto Salzano

Received: 17 September 2021

Accepted: 18 October 2021

Published: 25 October 2021

Publisher's Note: MDPI stays neutral with regard to jurisdictional claims in published maps and institutional affiliations.

Copyright: (c) 2021 by the authors. Licensee MDPI, Basel, Switzerland. This article is an open access article distributed under the terms and conditions of the Creative Commons Attribution (CC BY) license (https:// creativecommons.org/licenses/by/ $4.0 /)$.

\begin{abstract}
On 2 October 2003 in Saint-Romain-en-Jarez (France) a fire in a farm building triggered an explosion in which 26 people were injured. Police investigation, based solely on an analysis of the effects and on general engineering knowledge, showed that the explosion was caused by an uncontrollably generated mixture of ammonium nitrate (AN) and molten plastic crates which formed an explosive mixture similar to ammonium nitrate fuel oil (ANFO). This is the only commonly known example of an ammonium nitrate blast taking place at its end user destination. Is such an explanation of the incident plausible and could a similar blast possibly happen anywhere else? The experimental results support this thesis of French investigators but raise further doubts. Laboratory reconstruction of the self-acting process of generating the explosive material confirmed the investigators' report. However, other materials at the incident site could have influenced the final outcome too. The lab-recreated explosion of a mixture of AN and molten plastic partially confirmed the report's thesis.
\end{abstract}

Keywords: self-acting formation of explosives; ANFO; ammonium nitrate

\section{Introduction}

Due to the widespread use of ammonium nitrate(V) (AN) as the basic ingredient of fertilizers, there were tests carried out in order to complete a list of substances that may generate explosives in contact with AN under fire conditions. The event in question differs from the ones most frequently described both in scientific literature and in trade journals, as the explosion did not take place within a plant or where large amounts of AN are normally stored, but at the end user's-in this case a French farmer. However, such an accident could have happened anywhere else. Although the problem is much wider, only this specific event has so far been identified and analyzed in detail.

There were, i.a., a gasoline-powered forklift, agricultural machinery, two $13 \mathrm{~kg}$ gas cylinders, $500 \mathrm{~kg}$ quicklime, 500 wooden boxes, $6000-7000$ plastic boxes and $3-5$ tons of AN in $500 \mathrm{~kg}$ flexible intermediate bulk containers stored in the barn. Bales of hay and straw were stored on the mezzanine and about $500 \mathrm{~kg}$ of apples was kept in the cold storage in the attic. The fire started at 15:00. Firefighters were notified of the fire an hour later, and, upon reaching the scene, they began extinguishing at 16:23. The explosion took place at 17:12, as a result of which 26 people were injured, most of them firefighters. An investigation led by the police experts found that the explosive, which detonated as a result of high temperature of the fire environment, was a mixture of $\mathrm{AN}$ with molten polyethylene (PE) or polypropylene (PP) from the fruit crates.

Reactivity of AN is strongly influenced by the presence of other compounds (including impurities) which catalyze decomposition reactions, leading to thermal destabilization [1] Therefore, understanding interactions of AN with other compounds is essential for the safe storage and handling of materials containing AN. At the stage of production, storage, transport and usage, AN may be contaminated with various compounds such as inorganic 
acids, organic oils and others. Organic substances with a confirmed significant negative impact on the stability and safety of AN include: dinitrotoluene, nitronaphthalene and similar nitro compounds, ethylenediamine dinitrate, alkylamines and their salts, glycerol esters and aliphatic alcohols. The addition of ammonium chloride $\left(\mathrm{NH}_{4} \mathrm{Cl}\right)$ and rapid selfignition of the mixture in contact with metallic zinc $(\mathrm{Zn})$ is a classic example [2]. Research on the influence of a microstructured charcoal additive on the properties of ammonium nitrate fuel oil (ANFO), first proposed by Cornet and Boodberg in 1953, was published in $[3,4]$ and the influence of silicon dioxide in [5]. Polyolefin-waste-derived pyrolysis fuel oils were also used as a substitute and it was checked as to whether they could be used as a fuel component for ANFO [6,7]. Another examined aspect was the influence of AN granulation [8] and porosity [9] on the thermal decomposition of ANFO. However, the influence of many organic compounds on the thermal stability of AN has not been clearly defined so far. Once mixed with numerous substances, nitrates form explosive or self-igniting mixtures [10]. Table 1 contains substances that have an impact on AN decomposition and that were not taken into consideration within the report, even though they had been stored in the described facility — quicklime in the amount of $500 \mathrm{~kg}$ (exact location not specified) and water used by firefighters to extinguish the fire [11].

Table 1. Influence of selected ammonium nitrate (AN) additives on the temperature of the mixture's decomposition initiation.

\begin{tabular}{|c|c|c|c|c|c|c|c|c|}
\hline \multirow{2}{*}{$\begin{array}{c}\text { AN } \\
\text { Content (Analytical } \\
\text { Grade), Mass } \%\end{array}$} & \multicolumn{2}{|c|}{ Additive } & \multicolumn{3}{|c|}{ Temperature, ${ }^{\circ} \mathrm{C}$, of Mass Loss of Mass $\%$} & \multirow{2}{*}{$\begin{array}{c}\text { Total Mass } \\
\text { Loss, Mass } \\
\quad \%\end{array}$} & \multicolumn{2}{|c|}{$\begin{array}{l}\text { Temp. at the Beginning of } \\
\text { Sample Decomposition, }{ }^{\circ} \mathrm{C}\end{array}$} \\
\hline & Name & $\begin{array}{l}\text { Content, } \\
\text { Mass \% }\end{array}$ & 0.0 & 10.0 & 50.0 & & Endothermic & Exothermic \\
\hline 95.2 & $\mathrm{H}_{2} \mathrm{O}$ & 4.8 & 123 & 230 & 255 & 100.0 & 249 & 215 \\
\hline 80.0 & Quicklime & 20.0 & 35 & 142 & - & 47.8 & 100 & 272 \\
\hline
\end{tabular}

Obtaining liquid PE and PP from fruit crates is very simple under fire conditions, even if the fire source is located at a considerable distance from the material in question, because the average fire temperature in the developed phase reaches $600{ }^{\circ} \mathrm{C}$ [12-14], and the thermal radiation from the top layer is able to melt the two substances. Their melting point is, respectively: approx. $130^{\circ} \mathrm{C}$ for PE and approx. $160^{\circ} \mathrm{C}$ for PP [15].

\section{Materials and Methods}

In order to verify the thesis of French investigators about the cause of the explosion, there was a series of thermal analyses of AN mixtures carried out on the two most common polymers in this type of packaging-PE and PP [16]. The analysis of the effect of additives on the decomposition process was carried out using a differential scanning calorimeter (DSC) and a thermogravimetric analyzer (TGA), taking into account several parameters such as the composition of the mixture and the heating rate of the samples.

Measurement methodology, very high sensitivity of the apparatus and the risk of its damage during a potential explosion require the use of a small mass of the tested sample [17] - about $5 \mathrm{mg}$. For this reason, there was a decision made to crush the granular materials present in the sample, thanks to which it was possible to transfer the ratio of their size and geometry from the real scale to the microscale. The materials were mechanically disintegrated in liquid nitrogen atmosphere, thanks to which the heat released as a result of friction did not lead to irreversible changes in their structure [18]. Then, the samples were fractionated using sieves, the $0.29-0.1 \mathrm{~mm}$ fraction was dried in a chamber dryer at $28{ }^{\circ} \mathrm{C}$ and in negative pressure of $25 \mathrm{kPa}$ for $24 \mathrm{~h}$ and then placed in a desiccator under nitrogen atmosphere for another $48 \mathrm{~h}$. Such a process was necessary due to the hygroscopicity of AN; even a slight dampness of the material could significantly affect the obtained results [19].

The components of the mixture for analysis were weighed with an accuracy of $\pm 0.01 \mathrm{mg}$, and then a sample of $5.00 \pm 0.15 \mathrm{mg}$ was placed in an analytical $25 \mu \mathrm{L}$ aluminum vessel with a lid with a hole of $0.3 \mathrm{~mm}$ in diameter. The opening in the upper part of the 
vessel allowed for the removal of exhaust gases and minimized the pressure increase inside the vessel, thanks to which the obtained results to a greater extent reflected the influence of the temperature alone on the sample decomposition [20]. DSC analysis was performed on a DSC 3500 Sirius NETZSCH apparatus in the range of $25-400{ }^{\circ} \mathrm{C}$ under nitrogen atmosphere with a constant flow of $50 \mathrm{~mL} / \mathrm{min}$. The sample was heated at a rate of 2 or $10^{\circ} \mathrm{C} / \mathrm{min}$ in a linear manner. The value of the DSC signal was measured every $0.1^{\circ} \mathrm{C}$.

\section{Results}

Ammonium nitrate (AN) is a polymorphic substance, which means that in specific temperature ranges it occurs in a specific crystalline form [21]. These are endothermic changes, as are the melting (about $169^{\circ} \mathrm{C}$ ) and thermal decomposition (about $281^{\circ} \mathrm{C}$ ) of $\mathrm{AN}$ at atmospheric pressure. This means that while the processes in question take place, heat is extracted from the environment [22]. Under high pressure conditions which may occur, for example, during improper storage of $\mathrm{AN}$, the decomposition reaction may be exothermic, i.e., accompanied by the release of heat [23]. In the case of the tested polymers, the observations are quite similar-for pure materials, an endothermic melting process and an exothermic decomposition can be observed. They differ in the temperatures of the process $\left(135{ }^{\circ} \mathrm{C}\right.$ for $\mathrm{PE}$ and $170{ }^{\circ} \mathrm{C}$ for $\left.\mathrm{PP}\right)$ and the course of reaction, but none of them is explosive; in both cases, a gradual and slow release of heat appears. AN decomposes into gaseous products-depending on the reaction conditions it can be nitrogen gas, its oxides, oxygen and water vapor [24]. Gases, being released, lead to an increase in pressure, and if the appropriate conditions are met, a shock wave may arise. To sum up, thermal decomposition of pure AN, PE and PP is constituted of relatively safe reactions if carried out in a controlled manner.

However, the course of the reaction is entirely different when $\mathrm{AN}$ is mixed with any of the tested substances, as shown in Figures 1 and 2. The admixture of $20 \%$ polymer in both cases results in the formation of high-energy mixtures that decompose in a potentially explosive manner. The decomposition of the mixtures is rapid and accompanied by significant amounts of released heat- $1496 \mathrm{~J} / \mathrm{g}$ for a mixture with PE and $1310 \mathrm{~J} / \mathrm{g}$ for a mixture with PP. Another significant change which can be observed from the safety point of view is the temperature of the decomposition process initiation. The presence of the polymer results in a significant reduction of the reaction temperature. In the case of PE addition, the decomposition reaction begins at $257^{\circ} \mathrm{C}$ and in the case of $\mathrm{PP}$, at $270{ }^{\circ} \mathrm{C}$. By comparison, pure AN decomposes at around $281^{\circ} \mathrm{C}$. Moreover, the results show that decomposition of both mixtures is complete before decomposition of pure AN even begins. Depending on the distance from the heat source and its temperature in real conditions, such a difference may translate into a significant reduction in the amount of time in which actions can be taken to prevent a catastrophe in the event of fire on the site.

In the case of crystallographic changes reaction and melting of $\mathrm{AN}$, no significant changes were observed from the safety point of view. These are still endothermic processes. There are some shifts in reaction temperatures and their enthalpies, but they should not significantly affect the behavior of the mixture in relation to pure AN. The major change can be the formation of local polymer melt structures if the temperature rises above the melting point of the polymer but below that of AN. The presence of such structures can be disadvantageous due to the possibility of frictional heat generation during the transport of the fertilizer.

The influence of the amount of polymer on the course of the thermal decomposition of the mixture is different for both tested polymers, as shown in Figures 3 and 4 . In both cases the addition of about $20 \%$ by mass of polymers turns out to be the most dangerous due to the highest values of released heat; moreover, the process takes place in the most rapid way possible. Increasing the amount of polymer to $50 \%$ results in a lower thermal effect in both tested samples. Another difference from the mixture with $20 \%$ polymer addition is that after the main decomposition process, further decomposition reactions take place in the sample. This may be explained by the mass of the solid residue which remains after the 
sample decomposition. In the case of the PE mixture with a higher polymer content, the residue mass constitutes more than $20.7 \%$ of the original sample mass, compared to about $9 \%$ for the sample with lesser content of polymer.

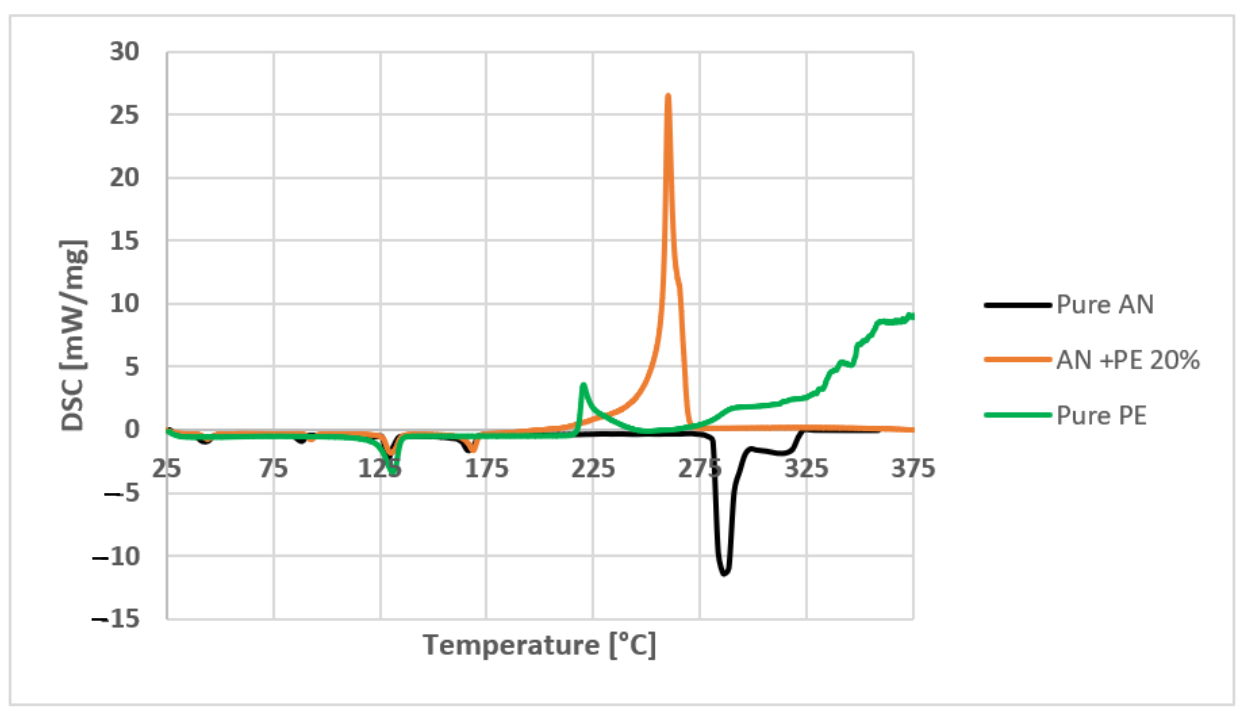

Figure 1. Differential scanning calorimeter (DSC) analysis showing the course of reaction of pure ammonium nitrate (AN), pure polyethylene (PE) and their mixture (containing $20 \%$ of the polymer), heat rate $10{ }^{\circ} \mathrm{C} / \mathrm{min}$.

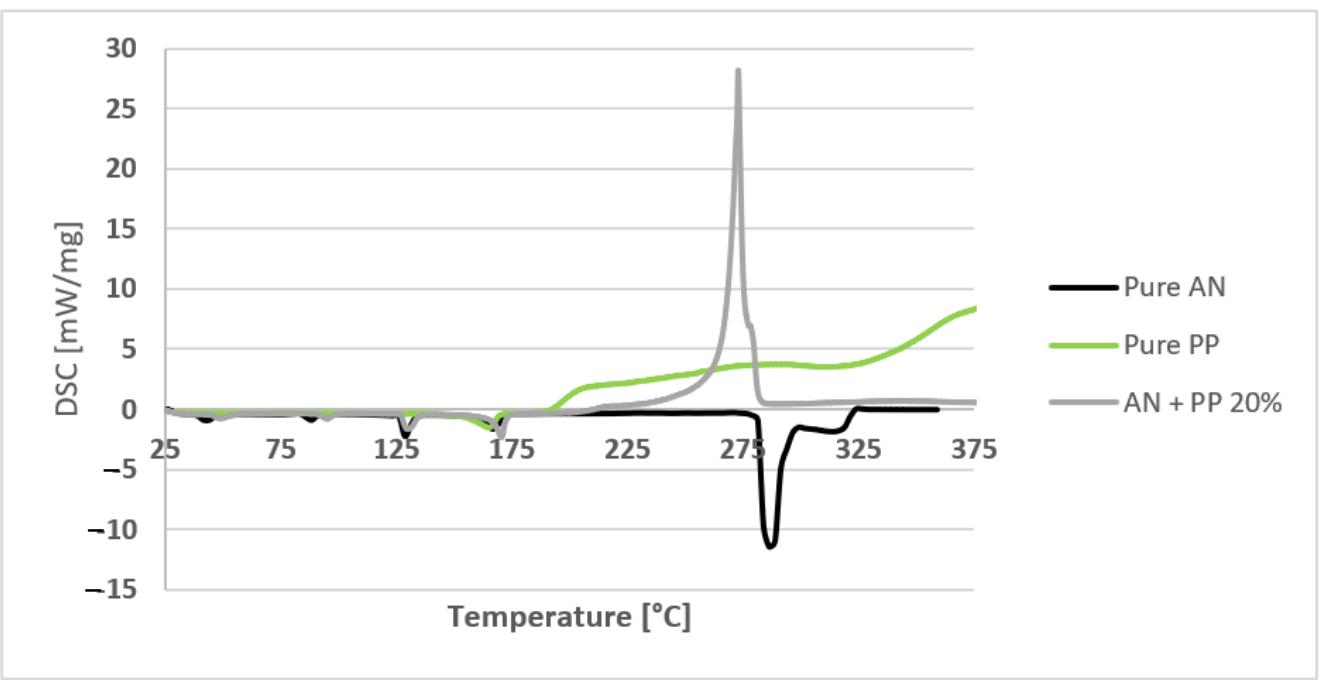

Figure 2. DSC analysis showing the course of reaction of pure AN, pure polypropylene (PP) and their mixture (containing $20 \%$ of the polymer), heat rate $10{ }^{\circ} \mathrm{C} / \mathrm{min}$.

Coming to PP, we do not observe a significant change in the temperature of the decomposition reaction along with the change in the amount of polymer in the sample, which is illustrated in Figure 4. This is different in the case of PE. The addition of 50\% of polymer causes an earlier initiation of the reaction at $232.8^{\circ} \mathrm{C}$ compared to $257.1^{\circ} \mathrm{C}$. In addition, a melting reaction residue can be observed in the PE mixture, which is not the case in the PP mixture. Furthermore, the enthalpy of PE decomposition reaction has a much lower value-968 J/g compared to $1496 \mathrm{~J} / \mathrm{g}$. For PP, this difference constitutes $757 \mathrm{~J} / \mathrm{g}$ compared to $1310 \mathrm{~J} / \mathrm{g}$. In the sample with a PE content of about $8 \%$-which is equivalent to the amount of organic oil in ANFO, a popular explosive [25] - the course of the decomposition reaction initiation is similar to the sample with $20 \%$ polymer addition. However, it is not so rapid, because the reaction ends at about $275^{\circ} \mathrm{C}$, compared to $265^{\circ} \mathrm{C}$, 
and less heat is released during its course. Nevertheless, in all the discussed mixtures, a significant amount of energy is released which, even if it does not initiate an explosion, may lead to the initiation of other processes inside the stored deposit.

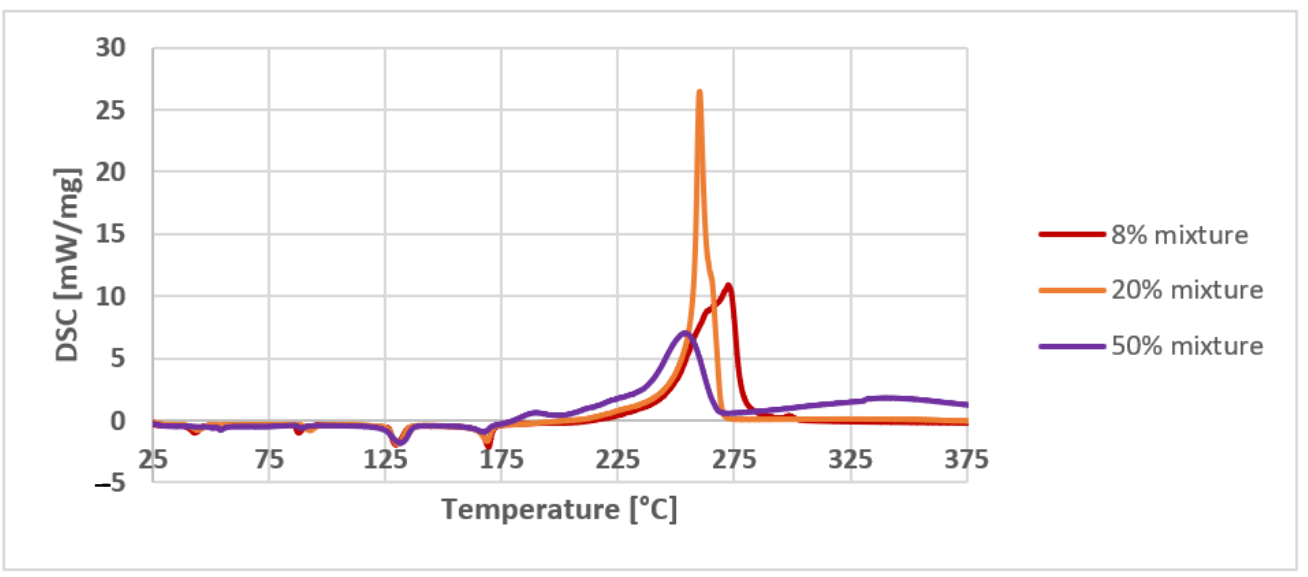

Figure 3. DSC analysis showing the influence of AN and PE mixture composition on the mixture's thermal properties, heat rate $10{ }^{\circ} \mathrm{C} / \mathrm{min}$.

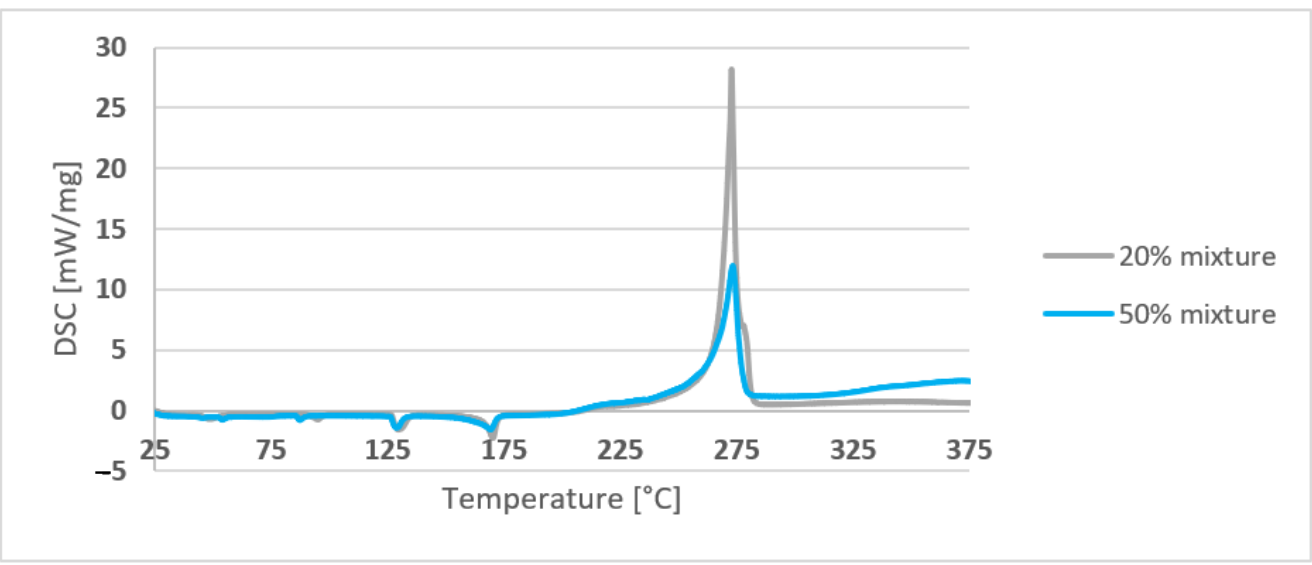

Figure 4. DSC analysis showing the influence of AN and PP mixture composition on the mixture's thermal properties, heat rate $10{ }^{\circ} \mathrm{C} / \mathrm{min}$.

Another case for which the analysis was carried out is the slow heating of the mixture, as shown in Figures 5 and 6. This may occur when the stored material is not in the vicinity of the fire source or when it is located in another room. The results show that reducing the heating rate of the material from 10 to $2{ }^{\circ} \mathrm{C} / \mathrm{min}$ for mixtures containing $20 \%$ of the polymer leads to a significant reduction in the initiation temperature of the decomposition reaction $-216.4^{\circ} \mathrm{C}$ for $\mathrm{PE}$ and $226.4^{\circ} \mathrm{C}$ for PP. Similar behavior can also be observed for pure $\mathrm{AN}\left(268.3^{\circ} \mathrm{C}\right)$. However, the amount of heat released is significantly lower than in the discussed case, and the reaction itself is not explosive. This does not mean that this is a safe process - the heat released in its course may initiate further processes inside the stored material, which may lead to an explosion.

Laboratory tests using, as samples, mixtures of AN and powdered PE and PP (from the original fruit crates) with different percentage composition show that an explosion can occur regardless of the proportions of both materials. Even a small addition of polymerwhich may appear during the transport of the material as a result of NA granules rubbing against the walls of polymer packaging-may, in extreme cases, lead to an explosion. The main difference between substances is the energy released during decomposition and the temperature at which decomposition takes place. Due to the lack of detailed data on the initial amounts of substances which uncontrollably formed an explosive resembling ANFO 
in its chemical composition, and the inability to determine the amount of substances that reacted, calculation methods were used to reproduce the effects of the explosion recorded at the scene (see Table 2), presenting several possible variants. The research did not take into account the very probable impurities that could have emerged due to the ammonium nitrate being stored for a long time, as well as the influence of quicklime and water used for extinguishing purposes in the course of the reaction.

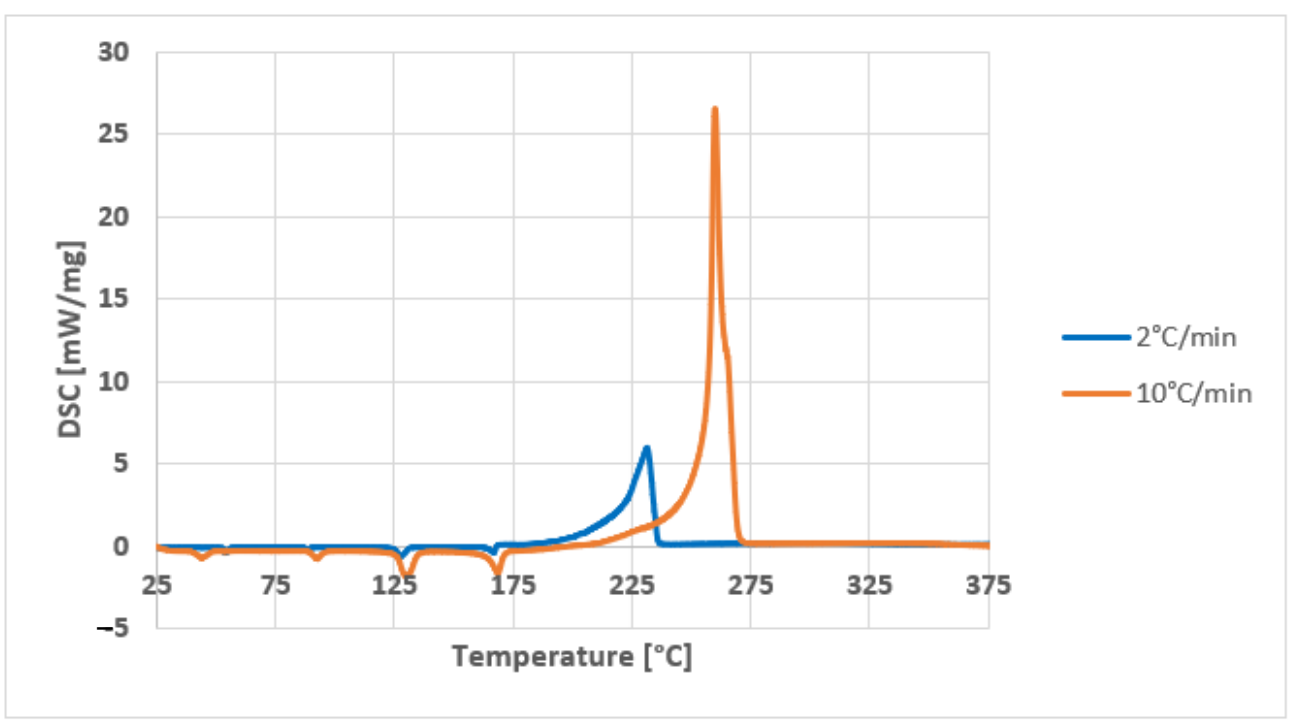

Figure 5. DSC analysis of AN and PE mixture (containing $20 \%$ of the polymer) for different heat rates.

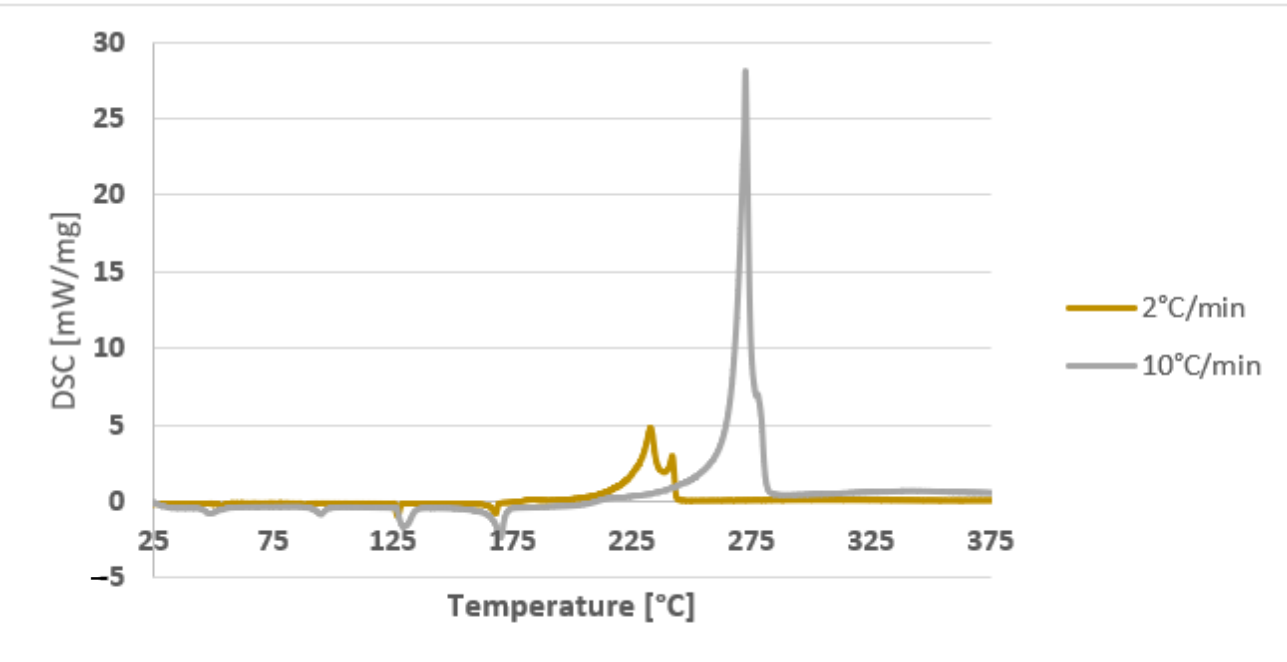

Figure 6. DSC analysis of AN and PP mixture (containing $20 \%$ of the polymer) for different heat rates.

Table 2. Damage extent and types after the explosion ${ }^{1}$.

\begin{tabular}{ccc}
\hline No. & Type of Damage & Damage Range \\
\hline 1 & Lightweight damage (broken glass panes, tile dislocation) & $650 \mathrm{~m}$ \\
2 & Major damage (cracked walls, chassis degradation) & 350 to $580 \mathrm{~m}$ \\
3 & Serious damage (structural deterioration, displaced partition walls) & $150 \mathrm{~m}$ \\
4 & Fragment projections & $800 \mathrm{~m}$ \\
\hline
\end{tabular}

${ }^{1}$ Fire inside a barn and explosion of fertilizer, 2 October 2003, Saint Romain-en-Jarez (Loire) France. French Ministry for Sustainable Development-DGPR/SRT/SDRA/BARPI, Aria Report No. 25669. 
Heat rate influence is shown in the chart (Figure 7).

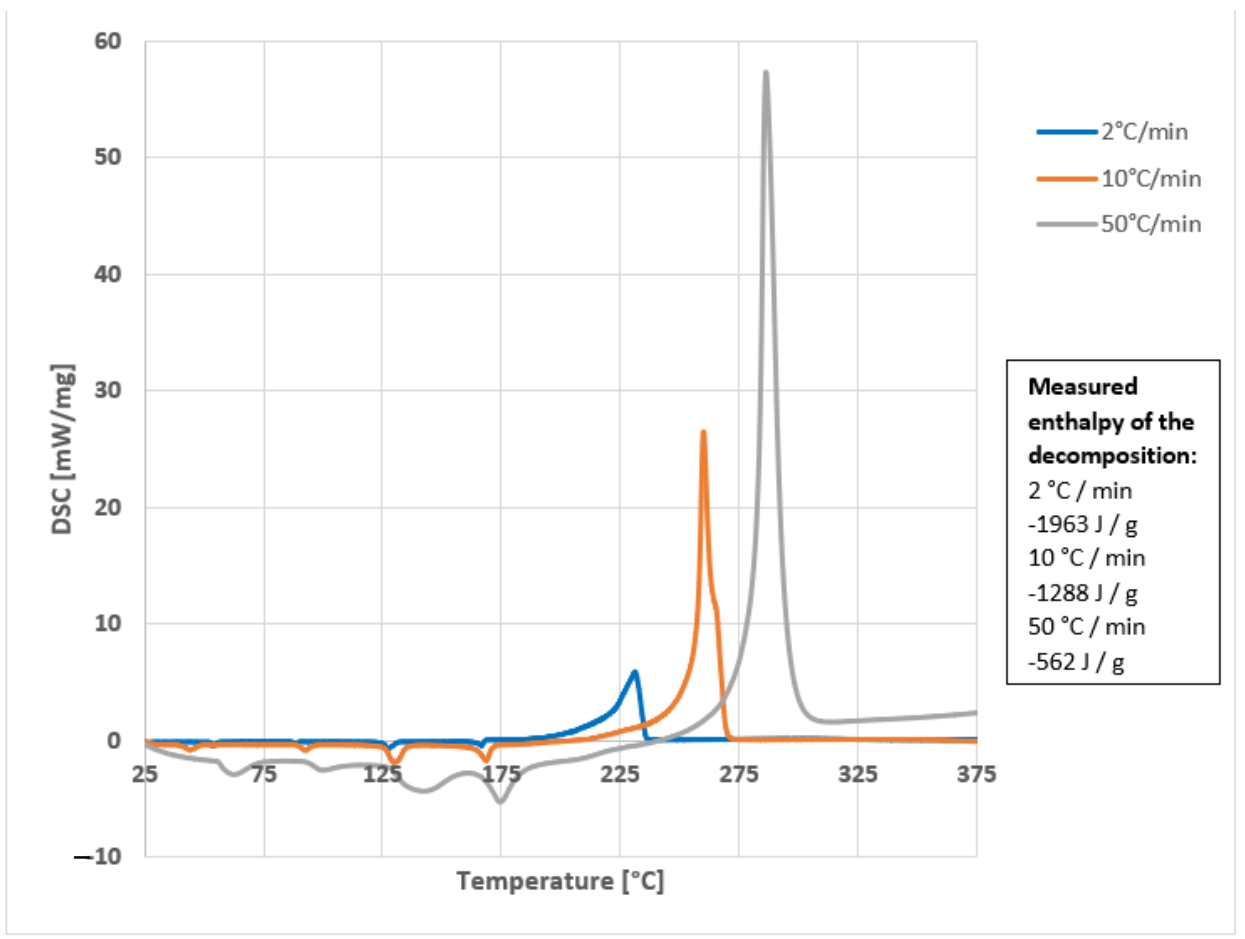

Figure 7. DSC analysis of AN and PE mixture (containing 20\% of the polymer) and thermal effect of the decomposition reaction for different heat rates.

The enthalpy of reaction can be determined by several different methods. One of the most frequently used is the method based on theoretical calculations. Having knowledge of its mechanism as well as of its chemical and physical course, it is possible to determine the reaction on the basis of balance calculations. The obtained results allow one to receive precise values for the enthalpy of the reaction. This facilitates the modeling of the processes in which this reaction may occur due to the full control of the course of the process in a function, e.g., the degrees of reaction. This method also has a number of disadvantages. One of them is the need to possess detailed practical knowledge about the conditions of the course of the reaction and the influence of factors that may modify it. It is difficult to take into account some additional phenomena which occur in the sample during a practical experiment (e.g., the degree of mixing). For the decomposition reaction in question, such phenomena include polymorphism, and additionally, the geometry of nitrate and polymer particles, the influence of possible impurities and humidity as well as the scattering of a part of the material during an explosion. During the DSC measurement, it is possible to determine the enthalpy of the reaction by measuring the area under the chart for the given peaks. This is due to the equation:

$$
\frac{d Q}{d t}=C_{p} \frac{d T}{d t}+f(T, t)
$$

where:

$d Q / d t$-differential heat flow rate $[\mathrm{W}]$,

$C_{p}$-heat capacity [J/K],

$d T / d t$-heat rate $\left[{ }^{\circ} \mathrm{C} / \mathrm{min}\right]$,

$f(T, t)$-kinetic heat flow [W].

This procedure allows accurate measurement of enthalpy under real-world conditions, but it is very sensitive to the value of heat flux supplied to or received from the sample during the DSC measurement. This is due to several phenomena. The most important issue is 
that the thermal conductivity of the analyzed sample is relatively low. Consequently, there is a difference between the temperature of the surface of the sample and its interior. This difference increases significantly with the value of supplied heat per unit of measurement time. For this reason, a phenomenon called temperature lag or thermal inertial effect occurs, where certain reactions inside the sample take place later than on its surface. Moreover, as the heat flux increases, the reaction time of the test equipment increases. When making a series of measurements, the heat flux of the same value and samples of the same size should be used. Thanks to this, it is possible to compare the thermal effects of the reaction on the basis of a graphical comparison of the area of the peaks.

In the case described in this article, the fact that the analyzed samples are twocomponent mixtures constitutes an additional difficulty. The components of these mixtures differ from each other in terms of both temperatures and thermal effects of changes, including melting. During the heating procedure we are dealing with a changing mixture of a varied structure-from a mixture of bodies with a crystalline and semi-crystalline structure (polymer), through a semi-liquid mixture to a completely liquid mixture which then decomposes, forming gaseous products. Both thermal parameters, such as thermal conductivity coefficients, and the geometry of the system (air present between the particles of the substance, which is absent in the molten polymer) significantly hinder making a description-based on calculations only-of the phenomenon which would reflect the actual behavior of the material. For this reason, in the conducted research, it was decided to present the practical enthalpy values obtained directly during the DSC measurement.

\section{Discussion}

The knowledge derived from the research results is intended to help not only the intervention services to plan rescue operations and decide on the time and area from which people at risk of consequences of a potential explosion should be evacuated, but also to prepare and develop social campaigns targeted at the end users-i.e., farm owners-in order to eliminate potential threats. According to the analysis of the available scientific literature, the number of substances that can potentially react with ammonium nitrate is much greater than that which remains in the public consciousness. The conducted laboratory tests are intended to provide the initial research material for the assessment of the time that, under certain conditions, is available to rescuers between a fire and the probable time of unprompted emergence of an explosive in the fire environment. This can improve the safety of rescuers and bystanders in the event of fires in facilities containing components (e.g., soybean oil [26]) that could potentially produce an ANFO-like explosive in an uncontrolled manner. This similarity results not only from the similar chemical structure of the organic substance in the mixture, but also from the similar course of the decomposition reaction. Importantly, it is hard to believe that with a huge number of events, there is only one case of an explosion of this type that has been confirmed. One hundred years of history of the massive use of AN resulted in numerous disastrous events: starting with the Oppau explosion in 1921 [27] and ending with the Beirut explosion in 2020 [28] with many other significant blasts in the meantime, such as the one in a fertilizer production plant in Toulouse, France [29] in 2001.

The incident in the French department of Loire is unusual-for the first time it became known to the public that although trace amounts of AN are stored in farm premises (compared to chemical factories or large warehouses, e.g., in ports), they can cause unnaturally rapid development of fire or, under specific conditions, cause explosions in farm buildings. It turns out that even ordinary plastic apple crates can be a component of a strong explosive. Due to the widespread use of artificial fertilizers based on AN on a global scale, in almost all climate conditions in millions of farms, in the authors' opinion the explosion in SaintRomain-en-Jarez has not been the only one that arose as a result of self-acting production of explosive material. During other proceedings, the actual causes of the incident may have gone undetected and their effects may have been attributed to other factors. The conducted 
laboratory tests did not concern animals directly and did not pose a threat to human health and life.

\section{Conclusions}

The conducted research showed that the two most popular plastics in combination with ammonium nitrate(V) (AN) or artificial fertilizers based on this substance, under fire conditions, pose a real threat of a significant increase in the fire dynamics or even an explosion. The results of the analyses and considerations about what may be stored in farm buildings led to the decision to undertake further laboratory research. This time, other plastics which are components of building materials have been adopted as agents that can produce an explosive in a mixture with AN. An answer is to be sought as to whether storing such materials in the immediate vicinity of $\mathrm{AN}$ is likely to cause analogous, rapid exothermic reactions which may bring about similar effects as those described in this study. If such an event occurs, there may always appear a suspicion of intentional human activity, unless detailed analyses are carried out [30]. It is also worth paying attention to how the reaction is initiated. In the described case, the heating process was a consequence of fire development, but the cause can also be mechanical, e.g., an explosion of a smaller charge or other material as well as strike, light or electric current, or contact with another chemical substance [31]. AN contamination with metal shavings or powdered metal dramatically increases the explosion force [32]. It can also be the result of deliberate action or simply improper storage of the fertilizer in the utility room. Thus, this aspect is also worth a deeper analysis and conduction of appropriate trials, preceded by on-site verification of buildings. The ethical review and approval were waived for this study due to the lack of any effects on humans and animals.

Author Contributions: Conceptualization, P.W. and S.K.; methodology, S.K.; validation, S.K. and P.W.; formal analysis, A.L. and F.M.; investigation, P.W. and N.T.; resources, N.T., P.W. and A.L.; data curation, S.K.; writing —original draft preparation, N.T. and P.W.; writing-review and editing, S.K., N.T. and F.M.; visualization, F.M. and A.L.; supervision, S.K. and P.W.; project administration, N.T. and S.K. All authors have read and agreed to the published version of the manuscript.

Funding: This research received no external funding.

Institutional Review Board Statement: Not applicable.

Informed Consent Statement: Not applicable.

Conflicts of Interest: The authors declare no conflict of interest.

\section{References}

1. DuTeaux, S. Texas City Disaster. In Encyclopedia of Toxicology, 3rd ed.; Elsevier BV: Amsterdam, The Netherlands, 2014; pp. 519-520.

2. Bretherick, L. Bretherick's Handbook of Reactive Chemical Hazards, 4th ed.; Elsevier BV: Amsterdam, The Netherlands, $1990 ;$ p. 1248.

3. Atlagic, S.G.; Biessikirski, A.; Kuterasinski, Ł.; Dworzak, M.; Twardosz, M.; Sorogas, N.; Arvanitidis, J. On the Investigation of Microstructured Charcoal as an ANFO Blasting Enhancer. Energies 2020, 13, 4681. [CrossRef]

4. Biessikirski, A.; Atlagić, S.G.; Pytlik, M.; Kuterasiński, Ł.; Dworzak, M.; Twardosz, M.; Nowak-Senderowska, D.; Napruszewska, B. The Influence of Microstructured Charcoal Additive on ANFO's Properties. Energies 2021, 14, 4354. [CrossRef]

5. Biessikirski, A.; Barański, K.; Pytlik, M.; Kuterasiński, Ł.; Biegańska, J.; Słowiński, K. Application of Silicon Dioxide as the Inert Component or Oxide Component Enhancer in ANFO. Energies 2021, 14, 2152. [CrossRef]

6. Biessikirski, A.; Czerwonka, D.; Biegańska, J.; Kuterasiński, Ł.; Ziąbka, M.; Dworzak, M.; Twardosz, M. Research on the Possible Application of Polyolefin Waste-Derived Pyrolysis Oils for ANFO Manufacturing. Energies 2020, 14, 172. [CrossRef]

7. Nowicki, L.; Siuta, D.; Markowski, M. Carbon Dioxide Gasification Kinetics of Char from Rapeseed Oil Press Cake. Energies 2020, 13, 2318. [CrossRef]

8. Biessikirski, A.; Kuterasiński, Ł.; Dworzak, M.; Twardosz, M.; Tatko, M.; Napruszewska, B.D. On the Influence of the Ammonium Nitrate(V) Provenance on Its Usefulness for the Manufacture of ANFO Type Explosives. Energies 2020, 13, 4942. [CrossRef]

9. Biessikirski, A.; Pytlik, M.; Kuterasiński, Ł.; Dworzak, M.; Twardosz, M.; Napruszewska, B.D. Influence of the Ammonium Nitrate(V) Porous Prill Assortments and Absorption Index on Ammonium Nitrate Fuel Oil Blasting Properties. Energies 2020, 13, 3763. [CrossRef]

10. Xu, S.; Tan, L.; Liu, J.-P.; Chen, X.; Jiang, W.; Chen, Y.; Liu, D.-B. Cause analysis of spontaneous combustion in an ammonium nitrate emulsion explosive. J. Loss Prev. Process. Ind. 2016, 43, 181-188. [CrossRef] 
11. Han, Z.; Pasman, H.J.; Mannan, M.S. Extinguishing fires involving ammonium nitrate stock with water: Possible complications. J. Fire Sci. 2017, 35, 457-483. [CrossRef]

12. Drysdale, D.D. Encyclopedia of Physical Science and Technology, 3rd ed.; Academic Press: Cambridge, MA, USA, 2003.

13. Purser, D.; A Stec, A.; Hull, T.; Hull, R. Effects of the material and fire conditions on toxic product yields. In Fire Toxic; Woodhead Publishing Limited: Soston, UK, 2010; pp. 515-540.

14. Janssens, M.L. Material Flammability, Handbook of Environmental Degradation of Materials, 2nd ed.; William Andrew: Norwich, NY, USA, 2012.

15. Ahmad, I.; Khan, M.I.; Khan, H.; Ishaq, M.; Tariq, R.; Gul, K.; Ahmad, W. Pyrolysis Study of Polypropylene and Polyethylene Into Premium Oil Products. Int. J. Green Energy 2015, 12, 663-671. [CrossRef]

16. DGPR/SRT/SDRA/BARPI Fire Inside a Barn and Explosion of Fertilizer, Saint Romain-en-Jarez (Loire) Aria Report; No. 25669; French Ministry for Sustainable Development: Paris, France, 2003.

17. Liu, H.; Armand, J.; Bouzon, J.; Vergnaud, J. Effect of sample size and heating rate on the DSC process for reactions of high enthalpy. Thermochim. Acta 1988, 126, 81-92. [CrossRef]

18. Hoque, E.; Pant, C.S.; Das, S. Study on Friction Sensitivity of Passive and Active Binder based Composite Solid Propellants and Correlation with Burning Rate. Def. Sci. J. 2020, 70, 159-165. [CrossRef]

19. Elzaki, B.I.; Zhang, Y.J. Anti-hygroscopic surface modification of ammonium nitrate (NH4NO3) coated by surfactants. Arab. J. Chem. 2020, 13, 3460-3473. [CrossRef]

20. Cargina, S.; Rotureau, P.; Adamo, C. Study of incompatibilities of ammonium nitrate and its mechanism of decomposition by theoretical approach. Chem. Eng. Trans. 2013, 31, 823-828.

21. Wu, H.B.; Nin Chan, M.; Chan, C.K. FTIR Characterization of Polymorphic Transformation of Ammonium Nitrate. Aerosol Sci. Technol. 2007, 41, 581-588. [CrossRef]

22. Chaturvedi, S.; Dave, P.N. Review on Thermal Decomposition of Ammonium Nitrate. J. Energ. Mater. 2013, 31, 1-26. [CrossRef]

23. Due-Hansen, M.E. The Decomposition of Ammonium Nitrate under Fire Conditions-A Review of Ammonium Nitrate Thermolysis; Norwegian Defence Research Establishment: Kjeller, Norway, 2018.

24. Lurie, B.A.; Lianshen, C. Kinetics and mechanism of thermal decomposition of ammonium nitrate powder under the action of carbon black. Combust. Explos. Shock. Waves 2000, 36, 607-617. [CrossRef]

25. Maranda, A.; Paszula, J.; Zawadzka-Małota, I.; Kuczyńska, B.; Witkowski, W.; Nikolczuk, K.; Wilk, Z. Aluminum Powder In-fluence on ANFO Detonation Parameters. Cent. Eur. J. Energ. Mater. 2011, 8, 279-292.

26. Weeks, B.; Worsey, P.; Kosman, K.; Andershock, D. Soybean Oil, No Longer Just for Cooking. In Proceedings of the Annual Conference on Explosives and Blasting Technique; International Society of Explosives Engineers (ISEE): Cleveland, OH, USA, 1997.

27. Hörcher, U. Oppau 1921: U. Old Facts Revisited. Chem. Eng. Trans. 2016, 48, 745-750.

28. Pasman, H.J.; Fouchier, C.; Park, S.; Quddus, N.; Laboureur, D. Beirut ammonium nitrate explosion: Are not we really learning anything? Process. Saf. Prog. 2020, 39, e12203. [CrossRef]

29. Moreno, V.C.; Reniers, G.; Salzano, E.; Cozzani, V. Analysis of physical and cyber security-related events in the chemical and process industry. Process. Saf. Environ. Prot. 2018, 116, 621-631. [CrossRef]

30. Buczkowski, D. Ammonium nitrate-A treat of accidental explosion and terrorist attack. Chemik 2012, 66, 227-234.

31. Urbański, T. Chemia i Technologia Materiałów Wybuchowych; Publishing House of the Ministry of National Defense: Warsaw, Poland, 1955; p. 266.

32. Kuzmin, V.; Kozak, G.; Mikheev, D. Detonability of ammonium nitrate and mixtures on its base. Cent. Eur. J. Energ. Mater. 2010, 7, 335 . 